CIVIL ENGINEERING SYSTEMS 
Other engineering titles from Macmillan Education

Malcolm Bolton, A Guide to Soil Mechanics

J. G. Croll and A. C. Walker, Elements of Structural Stability

J. A. Fox, An Introduction to Engineering Fluid Mechanics, Second Edition

N. Jackson (ed.), Civil Engineering Materials, Second Edition

W. H. Mosley and J. H. Bungey, Reinforced Concrete Design

Stuart S. J. Moy, Plastic Methods for Steel and Concrete Structures

Ivor H. Seeley, Civil Engineering Quantities, Third Edition

Ivor H. Seeley, Civil Engineering Specification, Second Edition

J. D. Todd, Structural Theory and Analysis

E. M. Wilson, Engineering Hydrology, Second Edition 


\section{Civil Engineering Systems}

\section{Andrew B. Templeman}

Department of Civil Engineering

University of Liverpool

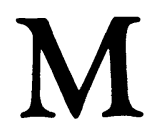


(C) Andrew B. Templeman 1982

All rights reserved. No part of this publication may be reproduced or transmitted, in any form or by any means, without permission.

First published 1982 by

THE MACMILLAN PRESS LTD

London and Basingstoke

Companies and representatives

throughout the world

Typeset in 10/12 pt Press Roman by

MULTIPLEX techniques ltd, Orpington, Kent

ISBN 978-0-333-28510-7

ISBN 978-1-349-86099-9 (eBook)

DOI 10.1007/978-1-349-86099-9

The paperback edition of the book is sold subject to the condition that it shall not, by way of trade or otherwise, be lent, resold, hired out, or otherwise circulated without the publisher's prior consent in any form of binding or cover other than that in which it is published and without a similar condition including this condition being imposed on the subsequent purchaser. 


\section{CONTENTS}

Preface viii

1 Systematic Decision-making in Civil Engineering 1

1.1 What is Civil Engineering Systems?

1.2 The Civil Engineering Project 4

1.3 Systematic Decision-making 11

1.4 Mathematical Decision-making Models 14

Summary 16

2 Systematic Mathematical Modelling - Linear Problems 17

Introduction 17

Example 2.1 - Earthmoving Operations 17

Example 2.2 - Precasting Plant 22

Example 2.3 - Rigid-Plastic Design of Frameworks 25

2.4 The General Linear Programming Problem 30

Summary 37

3 Solution Techniques for Linear Problems 38

Introduction 38

3.1 The Simplex Method for Linear Programming Problems 38

3.2 Sensitivity Analysis and LPs 58

3.3 Duality in Linear Programming 63

3.4 Other Methods for Solving LP Problems 66

$\begin{array}{lll}3.5 & \text { Negative Variables } & 67\end{array}$

3.6 Problems with Integer or Discrete-valued Variables 70

3.7 Civil Engineering Uses for Linear Programming 73

Example 3.8 - Water Resource Management 75

Summary 78

Bibliography $\quad 78$

$\begin{array}{ll}\text { Exercises } & 78\end{array}$ 
4 Project Planning Methods, Networks and Graphs 82

$\begin{array}{ll}\text { Introduction } & 83\end{array}$

4.1 Construction Planning Networks $\quad 83$

4.2 Linear Programming and Construction Planning Networks 97

4.3 Resource Allocation and Project Control 102

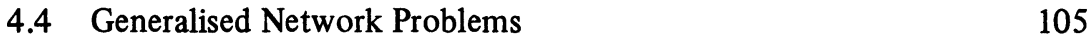

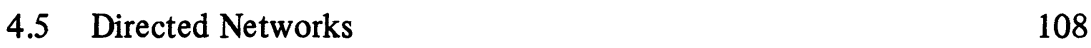

4.6 Undirected Networks and Graphs $\quad 119$

$\begin{array}{ll}\text { Summary } & 125\end{array}$

Bibliography $\quad 125$

$\begin{array}{ll}\text { Exercises } & 126\end{array}$

5 Serial Systems and Dynamic Programming 129

$\begin{array}{ll}\text { Introduction } & 129\end{array}$

Example 5.1 - A Critical Path Problem 129

5.2 Generalisation of the Network Approach 135

Example 5.3 - Allocating a Tower Crane 144

Example 5.4 - A Purification Process $\quad 148$

Example 5.5 - Drainage Design 152

5.6 Further Aspects of Dynamic Programming 157

$\begin{array}{ll}\text { Summary } & 163\end{array}$

$\begin{array}{ll}\text { Bibliography } & 163\end{array}$

$\begin{array}{ll}\text { Exercises } & 164\end{array}$

6 Systematic Design and Non-linear Problems 167

$\begin{array}{ll}\text { Introduction } & 167\end{array}$

$\begin{array}{lll}6.1 & \text { Systematic Design } & 167\end{array}$

$\begin{array}{lll}6.2 & \text { Simple Design Examples } & 171\end{array}$

6.3 Features of Non-linear Programming Problems 176

6.4 Engineering and Mathematical Viewpoints on 184

$\begin{array}{ll}\text { Summary } & 185\end{array}$

7 Non-linear Unconstrained Optimisation Methods 186

$\begin{array}{ll}\text { Introduction } & 186\end{array}$

7.1 The Classical Differential Method 186

$\begin{array}{ll}7.2 \text { Zeroth-order Methods } & 190\end{array}$

$\begin{array}{lll}7.3 & \text { First-order Methods } & 213\end{array}$

$\begin{array}{lll}7.4 & \text { Second-order Methods } & 224\end{array}$

7.5 Appropriate Methods for Engineering Problems 232

$\begin{array}{ll}\text { Summary } & 234\end{array}$

$\begin{array}{ll}\text { Bibliography } & 234\end{array}$

$\begin{array}{ll}\text { Exercises } & 235\end{array}$ 
CONTENTS

8 Non-linear Constrained Optimisation Methods

Introduction

8.1 Simple Solution Devices 238

8.2 Lagrange Multiplier Methods 241

8.3 Penalty Function Methods 249

$\begin{array}{lll}8.4 & \text { Linearisation Methods } & 257\end{array}$

8.5 Direct Numerical Search Methods 263

8.6 Geometric Programming 265

$\begin{array}{ll}\text { Summary } & 286\end{array}$

$\begin{array}{ll}\text { Bibliography } & 287\end{array}$

$\begin{array}{ll}\text { Exercises } & 287\end{array}$

9 Non-linear Optimisation in Civil Engineering 291

$\begin{array}{ll}\text { Introduction } & 291\end{array}$

9.1 Example - A Pumped Pipeline 292

9.2 Micro-design of Engineering Elements 297

9.3 Design of Multi-element Structural Systems 301

\begin{tabular}{ll}
9.4 & Other Non-linear Problems \\
\hline
\end{tabular}

$\begin{array}{ll}\text { Summary } & 309\end{array}$

$\begin{array}{ll}\text { Bibliography } & 309\end{array}$

$\begin{array}{ll}10 \text { Probabilistic Decision-making } & 310\end{array}$

$\begin{array}{ll}\text { Introduction } & 310\end{array}$

10.1 Deterministic and Probabilistic Quantities 311

10.2 Probabilistic Decision-making Problems 313

$\begin{array}{lll}10.3 & \text { Random Variables and their Properties } & 315\end{array}$

10.4 The Use of Expected Values for Decision-making 325

10.5 Maintenance and Replacement Problems 340

$\begin{array}{lll}10.6 & \text { Reliability } & 343\end{array}$

$\begin{array}{lr}\text { Summary } & 355\end{array}$

Bibliography $\quad 355$

$\begin{array}{ll}\text { Exercises } & 356\end{array}$

$\begin{array}{ll}\text { Solutions to Exercises } & 360\end{array}$

$\begin{array}{ll}\text { Index } & 366\end{array}$ 


\section{PREFACE}

Operations research, management science, mathematical optimisation and statistical decision-making are specialised disciplines which have blossomed since the Second World War. They are all concerned with quantitative methods for the solution of decision-making, planning and control problems in industrial and commercial enterprises. Many of the methods are applicable to a wide range of civil engineering problems and the profession is gradually accepting some of them and benefiting from their use. This book introduces some of the methods and concepts of these specialised disciplines which are particularly useful and applicable to practical civil engineering problems.

Civil engineering systems is, however, far more than a convenient holdall for diverse specialist mathematical methods. Civil engineering systems is concerned with decision-making processes within the civil engineering profession. It provides a logical, comprehensive framework for the study of civil engineering decision-making, and consequently many techniques from other disciplines which are concerned with decision-making naturally find a place in civil engineering systems.

The book is based on lecture courses given over a number of years to civil engineering students at the University of Liverpool. These courses present the practice of civil engineering as a creative, decision-making process for which a systematic approach and a knowledge of some efficient decision-making methods are invaluable. The material in this book is aimed at final-year undergraduate and master's degree levels although some of the topics could easily and appropriately be taught earlier. The book assumes a knowledge of simple differential calculus, vectors and matrices but all the mathematical methods described are developed simply and are self-contained. Only an elementary knowledge of technological theory and analysis, for example, structural mechanics and hydromechanics, is assumed. An important feature of the book is that civil engineering considerations are always uppermost. All mathematical methods are developed in a rigorous mathematical fashion but are only developed when a number of practical civil engineering problems have clearly 
demonstrated the need for a mathematical solution method. The theoretical aspects are illustrated as much as possible with detailed examples drawn from civil engineering. The arrangement of the book is as follows.

Chapter 1 is of an introductory nature, characterising civil engineering as a decision-oriented profession and examining the nature of the decisions that have to be made during the planning, design, construction and operation phases of a civil engineering project. The underlying aim of making the best possible decisions is presented as a process of optimisation. A four-stage systematic approach to decision-making, used frequently throughout the book, is introduced.

The next three chapters deal with linear decision-making models and methods. Chapter 2 uses civil engineering examples to illustrate the systematic approach and derives linear programming problems for each example. The nature of LP problems is examined. This leads naturally into chapter 3 where the simplex method for solving LP problems is presented. Several aspects of linear programming and its uses in civil engineering are examined. Chapter 4 deals with networks. It describes the critical path method of construction planning in its usual form, and then shows the basic linearity of the method by relating it to linear programming. The linearity is then used to examine other network problems and some simple graph problems are explained.

Chapter 5 covers dynamic programming in a non-classical fashion. A construction planning example is solved by constructing a network of possible solution policies. Methods from chapter 4 are then used to find an optimal path through the network and the algorithm is then generalised to become the DP method. Several further civil engineering problems are described and solved to illustrate many aspects of dynamic programming.

Chapters 6 to 9 are concerned with non-linear decision-making models and methods. Chapter 6 shows by simple examples that almost all civil engineering design problems are non-linear. Some general characteristics of non-linear optimisation problems are examined. Chapter 7 deals with solution methods for unconstrained optimisation problems and chapter 8 with methods for constrained optimisation. These chapters are the most mathematical in the book with very little civil engineering content. Chapter 9 balances the two previous chapters by concentrating on the civil engineering applications of non-linear optimisation. Several examples are studied in detail.

Chapter 10 deals with uncertainty in the decision-making process. The nature of the solutions to be expected when statistical information is introduced into a problem is examined and several statistical decision-making methods are presented using civil engineering examples. The concepts of reliability-based decision-making are examined.

Many of the chapters have a bibliography which suggests specialised texts for further reading. Also many chapters have a final section of problems for the reader to solve. For each problem the briefest of numerical solutions is provided at the back of the book. My experience is that students tend not to attempt to 
solve problems unless they have some way of telling whether their solutions are right or wrong.

The most difficult aspect of writing this book has been the conscious omission of useful and interesting topics. Those included are probably the major ones of interest to civil engineers, but who could argue that, for example, queuing theory or inventory theory are not also of use in civil engineering? They are omitted with reluctance along with many equally relevant and useful topics. The book is an introductory one to a very wide and diverse discipline. I hope that it will encourage others to explore this field for themselves and to be rewarded by the pleasure and stimulus which I have found there.

ANDREW TEMPLEMAN 